\title{
LEI GERAL DE PROTEÇÃO DE DADOS (LGPD) E AS COOPERATIVAS: IMPRESSÕES INICIAIS
}

\author{
GENERAL DATA PROTECTION LAW (LGPD) AND COOPERATIVES: \\ IMPLEMENTATION CHALLENGES
}

\section{LEY GENERAL DE PROTECCIÓN DE DATOS (LGPD) Y COOPERATIVAS: RETOS DE APLICACIÓN}

\author{
JosÉ RAPHAEL BATISTA FREIRE \\ https://orcid.org/0000-0001-7379-5084 / http://lattes.cnpq.br/2960862374855788 / joseraphaelbf@gmail.com \\ Pontifícia Universidade Católica do Paraná (PUCPR) \\ Curitiba, PR, Brasil
}

LEILA ANDRESSA DISSENHA

https://orcid.org/0000-0002-1675-0119 / http://lattes.cnpq.br/1229422381886989/ leilaandressa@yahoo.com.br Pontifícia Universidade Católica do Paraná (PUCPR)

Curitiba, PR, Brasil

\begin{abstract}
RESUMO
A Lei Geral de Proteção de Dados Pessoais (Lei $n^{\circ} 13.709 / 2018$ ) entrou integralmente em vigor no dia primeiro de agosto de 2021. Tal instrumento legal traz uma preocupação imediata aos empreendimentos quanto à sua aplicação e às implicações da realidade que impõe. As cooperativas, com toda sua importância econômica e social, assim como todas as demais organizações, devem se adequar aos parâmetros impostos pela nova lei. Este breve artigo, pautado nas referências bibliográficas existentes sobre o tema e no próprio texto legal, possui como objetivo uma análise dos desafios de implementação da Lei Geral de Proteção de Dados Pessoais nas Cooperativas, situando gestores, cooperados e colaboradores acerca da necessidade de criar estratégias para a implementação das exigências legais e, principalmente, alertar para as dificuldades que podem se apresentar neste processo e as consequências que podem advir da omissão diante do novo cenário criado para a proteção de dados. 0 método utilizado foi o dedutivo e dogmático. Por fim, o artigo está estruturado em introdução, desenvolvimento, conclusão e referências bibliográficas.
\end{abstract}

Palavras-chave: Cooperativas; LGPD; Proteção de Dados; privacidade.

\section{ABSTRACT}

The General Law for the Protection of Personal Data (Law No. 13.709/2018) came into full force on August 1, 2021. This legal instrument brings an immediate concern to enterprises regarding its application and the implications of the reality it imposes. Cooperatives, with all their economic and social importance, as well as all other organizations, must adapt to the parameters imposed by the new law. This brief article, based on existing bibliographic references on the subject and on the legal text itself, aims to analyze the challenges of implementing the General Law for the Protection of Personal Data in Cooperatives, situating managers, cooperative members and collaborators about the need to create strategies for the implementation of legal requirements and, mainly, to draw attention to the difficulties that may arise in this process and the consequences that may arise from the omission in the face of the new scenario created for the protection of personal data. The method used was deductive and dogmatic. Finally, the article is structured in introduction, development, conclusion and bibliographical references.

Keywords: Cooperative; LGPD; Data Protection, privacy.

\section{RESUMEN}

La Ley General de Protección de Datos Personales (Ley N 13.709/2018) entró en vigencia el 1 de agosto de 2021. Este instrumento legal trae una preocupación inmediata a las empresas por su aplicación y las implicaciones de la realidad que impone. Las cooperativas, con toda su importancia económica y social, así como todas las demás organizaciones, 
ISSN 1981-3694

(DOI): $10.5902 / 1981369441636$

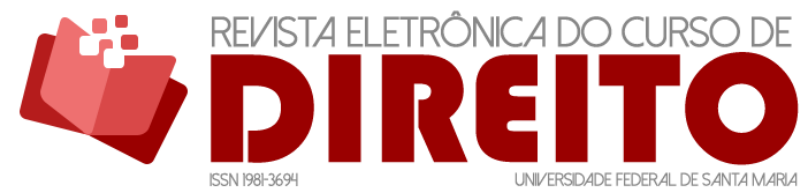

LEI GERAL DE PROTEÇÃO DE DADOS (LGPD) E AS COOPERATIVAS: IMPRESSÕES INICIAIS

José RAPHAEl BATISTA Freire LEILA ANDRESSA DISSENHA

deben adaptarse a los parámetros que impone la nueva ley. Este breve artículo, basado en referencias bibliográficas existentes sobre el tema y en el propio texto legal, tiene como objetivo analizar los desafíos de la implementación de la Ley General de Protección de Datos Personales en las Cooperativas, situando a los responsables, cooperativistas y colaboradores sobre la necesidad de crear estrategias para la implementación de requisitos legales y, principalmente, llamar la atención sobre las dificultades que puedan surgir en este proceso y las consecuencias que puedan derivarse de la omisión ante el nuevo escenario creado para la protección de datos personales. El método utilizado fue deductivo y dogmático. Finalmente, el artículo se estructura en introducción, desarrollo, conclusión y referencias bibliográficas..

Palabras clave: Cooperativas; LGPD; Protección de datos; privacidad.

\section{SUMÁRIO}

INTRODUÇÃO; 1 ASPECTOS GERAIS SOBRE A LEI GERAL DE PROTEÇÃO DE DADOS (LGPD) - LEI No. 13.709/18; 2 SOBRE O COOPERATIVISMO; 3 DESAFIOS DE IMPLEMENTAÇÃO PARA ADEQUAÇÃO DAS COOPERATIVAS À LEI GERAL DE PROTEÇÃO DE DADOS; CONCLUSÃO; REFERÊNCIAS.

\section{INTRODUÇÃO}

A Lei Geral de Proteção de Dados Pessoais (Lei nº 13.709/18), também conhecida como LGPD, surpreendeu muitos empreendimentos ao trazer um novo marco jurídico sobre o tema. A referida lei esclarece diversos conceitos e exige uma postura transparente e extremamente cautelosa no tratamento de dados pessoais por todos os empreendimentos, incluindo as Cooperativas.

A implementação das posturas exigidas não será simples, razão pela qual a Lei Geral de Proteção de Dados Pessoais foi publicada em 14 de agosto de 2018 e entrou integralmente em vigor no dia primeiro de agosto de 2021, nos termos do artigo 65, inciso I-A, da LGPD, conforme redação dada pela Lei n 14.010/2020. A LGPD ainda necessitará de regulamentação que ficará a cargo da ANPD (Autoridade Nacional de Proteção de Dados).

Valendo-se do método dedutivo, com a pesquisa dogmática evidenciando aspectos da atual normativa jurídica sobre a proteção de dados pessoais e impressões sobre ela presentes em artigos, livros, revistas e demais materiais bibliográficos disponíveis, busca-se apresentar o cenário acerca da proteção de dados aos gestores, cooperados e colaboradores das Cooperativas. Ademais, almeja-se contextualizar referidas organizações à luz da Lei Geral de Proteção de Dados Pessoais, especialmente sobre a preocupação com a proteção dos seus cooperados - 0 principal ativo dessa sociedade de pessoas. Assim, o objetivo geral se revela na análise dos desafios de implementação da Lei Geral de Proteção de Dados Pessoais nas Cooperativas, em razão da sua recente entrada em vigor. 
ISSN 1981-3694

(DOI): $10.5902 / 1981369441636$

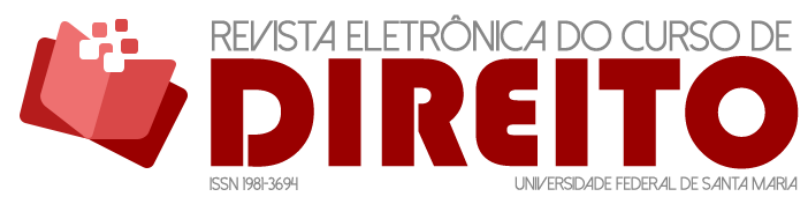

LEI GERAL DE PROTEÇ̃̃O DE DADOS (LGPD) E AS COOPERATIVAS: IMPRESSÕES INICIAIS

José RAPHAEL BATISTA FreiRE LEILA ANDRESSA DISSENHA

Pesquisas anteriores indicam o desconhecimento das organizações e dos colaboradores sobre Lei $\mathrm{n}^{\circ}$. 13.709/18, assim como suas práticas de proteção de dados ${ }^{1}$; portanto, as Cooperativas precisam iniciar seu processo de planejamento e adequação à Lei Geral de Proteção de Dados. Vale mencionar que cada ramo pode ser impactado de forma diferente e que alguns, por força de outros dispositivos legais, podem estar um passo à frente neste processo como é o caso das cooperativas de crédito, que já possuem Regulamentação do Banco Central acerca da segurança cibernética (Resolução $n^{\circ}$. 4.658/2018). Fato, contudo, é que nenhuma ficará à margem da exigência legal e as consequências para eventual descumprimento podem ser bastante onerosas, não apenas para os cooperados, como para todos os que participam da rede de pessoas e negócios que compõem o universo cooperativista.

0 artigo está estruturado em três grandes partes: introdução, desenvolvimento e conclusão. Inicialmente, na parte introdutória, explana-se uma visão geral da pesquisa. Em relação ao desenvolvimento, primeiramente demonstra-se um contexto geral da Lei Geral de Proteção de Dados (Lei $n^{\circ}$. 13.709/18), apresentando os aspectos gerais da legislação; na sequência, aborda-se sobre o cooperativismo, explanando sobre essa forma de organização, essencialmente sobre sua importância no cenário nacional em níveis sociais e mercadológicos; posteriormente, contemplando os dois tópicos anteriores, apresentam-se os desafios de implementação da Lei Geral de Proteção de Dados Pessoais nas Cooperativas, destacando os principais pontos de adequação, assim como elencando e exemplificando suas peculiaridades. Finalmente, relatam-se as conclusões advindas da presente pesquisa, apresentando-se os impactos inaugurais da Lei nas Cooperativas.

\section{ASPECTOS GERAIS SOBRE A LEI GERAL DE PROTEÇÃO DE DADOS (LGPD) -}

\section{LEI No. 13.709/18}

Em tempos de monitoramento extensivo, transmissões ao vivo e controle virtual massivo, a privacidade tornou-se mais que um direito a ser preservado: é um bem de valor inestimável. Na busca de proteção deste importante direito fundamental, e de forma a adequarse a legislações mais maturadas sobre o tema, foi publicada a Lei $\mathrm{n}^{\circ} 13.709$, de 14 de agosto de 2018, a Lei Geral de Proteção de Dados Pessoais (LGPD).

\footnotetext{
1 PIURCOSKY, F. et al. A lei geral de proteção de dados pessoais em empresas brasileiras: uma análise de múltiplos casos. SUMA DE NEGOCIOS, 10(23), p. 89-99, julio/diciembre, 2019. ISSN 2215-910X. Doi: http://dx.doi.org/10.14349/sumneg/2019.V10.N23.A2.
} 
ISSN 1981-3694

(DOI): $10.5902 / 1981369441636$

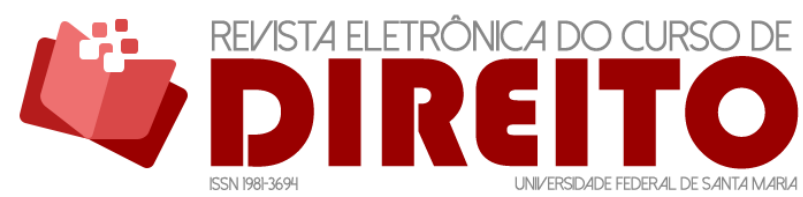

LEI GERAL DE PROTEÇÃO DE DADOS (LGPD) E AS COOPERATIVAS: IMPRESSÕES INICIAIS

José RAPHAEL BATISTA FreiRE LEILA ANDRESSA DISSENHA

A preocupação com a proteção dos dados pessoais é tamanha que está em trâmite uma Proposta de Emenda à Constituição (PEC) - número 17/19 - onde se busca inserir o inciso XII-A no rol do artigo $5^{\circ}$ da Constituição Federal de 1988. Em caso de aprovação, a proteção de dados pessoais (por meio físico e digital) passará a figurar como direito e garantia fundamental do cidadão.

Com a Lei Geral de Proteção de Dados, uma série de dúvidas e receios emergiram, indo além das preocupações com sua implementação. Sempre houve uma preocupação com o “invisível”. Em tempos mais remotos, ele era o Mercado, depois o Estado e, agora, a Tecnologia: o cuidado com os dados revela a preocupação com a manipulação do ser humano, com a indução de fatos e padrões ${ }^{2}$. Além disso, a regulamentação cria dois cenários importantes: o de ambiente jurídico para a proteção e o de condições jurídicas lícitas para que os dados sejam convertidos em mercadoria ${ }^{3}$.

Ademais, no contexto da Lei Geral de Proteção de Dados, estão expostas diferentes formas de preocupação de uso abusivo de dados pessoais: mineração para fins mercadológicos e publicitários, discriminação de qualquer espécie; divulgação dos dados do usuário sem o seu consentimento; troca prevenção a mecanismos diversos de fraude, por exemplo. A lei exige que medidas de segurança sejam tomadas para garantir a segurança e o sigilo de dados, além de sugerir a necessidade de formulação de programas de governança e manuais de boas práticas a fim de evitar e conter incidentes no tratamento destes dados.

Já foi observado que, além do risco de manipulação, em um ambiente de mercantilização dos dados, é possível a criação de um ciclo virtuoso (ou vicioso, a depender do ponto de vista): há a possibilidade de um entendimento melhor o seu titular, criando e oferecendo produtos e serviços melhores para ele como cliente, por exemplo, permitindo que ele consuma mais e, com isso, mais dados sejam gerados ${ }^{4}$. Numa Cooperativa, não raro, o Cooperado é, simultaneamente, sócio e cliente e este ciclo ganha uma importância ainda maior.

\footnotetext{
${ }^{2}$ SZINVELSKI, Mártin Marks, ARCENO, Taynara Silva e FRANCISCO, Lucas Baratieri. Perspectivas jurídicas da relação entre big data e proteção de dados. Perspectivas em Ciência da Informação [online], v. 24, n. 04, pp. 132-144, 2019. Disponível em: https://doi.org/10.1590/1981-5344/4188. Epub 10 fev 2020. ISSN 1981-5344. Acesso em: 19 nov. 2021.

3 FORNASIER, Mateus de Oliveira; KNEBEL, Norberto Milton Paiva. O titular de dados como sujeito de direito no capitalismo de vigilância e mercantilização dos dados na Lei Geral de Proteção de Dados. Revista Direito e Práxis, [S.l.], v. 12, n. 2, p. 1002-1033, jun. 2021. ISSN 2179-8966. Disponível em: https://www.e-publicacoes.uerj.br/index.php/revistaceaju/article/view/46944/33907. Acesso em: 20 nov. 2021.

${ }^{4}$ GARCIA, Lara Rocha; PINTO, Felipe Chiarello de Souza. Inovação e sua Principal Barreira Jurídica. Revista Eletrônica do Curso de Direito da UFSM, Santa Maria, RS, v. 15, n. 2, e41419, maio/ago. 2020.
} 
ISSN 1981-3694

(DOI): $10.5902 / 1981369441636$

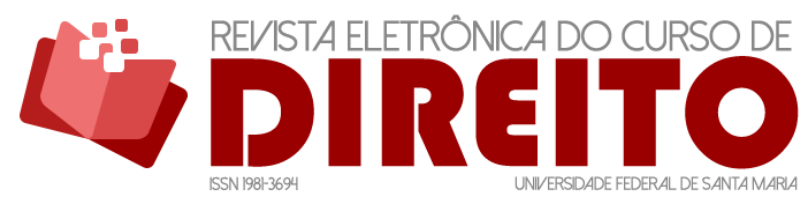

LEI GERAL DE PROTEÇÃO DE DADOS (LGPD) E AS COOPERATIVAS: IMPRESSÕES INICIAIS

José RAPHAEL BATISTA FreiRE LEILA ANDRESSA DISSENHA

Obviamente, entre a proteção contra exploração/manipulação e a criação de um ambiente jurídico transparente para o uso/tratamento dos dados, é necessário primar pela responsabilidade.

A LGPD foi inspirada na GDPR (General Data Protection Regulation) - regulamento que rege a proteção de dados na União Europeia, que entrou em vigor em 25 maio de 2018 (Regulamento $n^{\circ}$ 2016/679), substituindo a Diretiva 95/46/CE ${ }^{5}$, que “tem por objeto quaisquer tratamentos de dados pessoais"6. Contudo, o tema é regulamentado na União Europeia desde 1995, sendo que alguns países-membros tinham leis anteriores a essa data, como o Ato de Proteção de Dados de Hesse (1970, Alemanha), o Ato de Dados Sueco (1973).

O primeiro ato para proteger os dados na Europa se deu em 1981, quando o Conselho da Europa aprovou a Convenção $n^{\circ}$. 108. Posteriormente, editou-se a Diretiva 95/46/CE. Em verdade, a proteção dos dados se iniciou em 1948, quando da promulgação da Declaração Universal dos Direitos Humanos que, em seu artigo 12, declara a privacidade como um direito universal.

Não sem razão, o que se viu no contexto Europeu, nos últimos anos, foi o endurecimento das regras de responsabilidade sobre a proteção de dados, especialmente, nas legislações Estatais, multiplicando garantias, como ocorreu na Itália ${ }^{7}$ e criminalizando condutas mais graves, como ocorreu em Portugal ${ }^{8}$. Há pesquisadores, inclusive, propondo a ideia de uma proteção mais articulada em nível Europeu. ${ }^{9} \mathrm{Na}$ Itália, por exemplo, há cuidado e preocupação

ISSN 1981-3694. DOI: http://dx.doi.org/10.5902/1981369441419. Disponível em: https://periodicos.ufsm.br/revistadireito/article/view/41419. Acesso em: 20 nov. 2021.

${ }^{5}$ MENDES, Laura Schertel; DONEDA, Danilo. Reflexões iniciais sobre a nova lei geral de proteção de dados. Revista de Direito do Consumidor, vol. 120, p. 469-483, nov./dez. 2018.

${ }^{6}$ MASSENO, Manuel David. Como a União Europeia procura proteger os cidadãos-consumidores em tempos de Big Data. Revista Eletrônica do Curso de Direito da UFSM, Santa Maria, RS, v. 14, n. 3, e41708, set./dez. 2019. ISSN 1981-3694. DOI: http://dx.doi.org/10.5902/1981369441708. Disponível em: https://periodicos.ufsm.br/revistadireito/article/view/41708. Acesso em: 20 nov. 2021.

7 FIORINELLI, G. La moltiplicazione dei garanti nel settore della tutela dei dati personali: riflessi penalistici del GDPR. Rivista Trimestrale di Diritto Penale Contemporaneo, 2, 2019. ISSN 2240-7618. Disponível em: http://hdl.handle.net/2318/1719754. Acesso em: 19 nov. 2021.

8 MASSENO, Manuel David. Como a União Europeia procura proteger os cidadãos-consumidores em tempos de Big Data. Revista Eletrônica do Curso de Direito da UFSM, Santa Maria, RS, v. 14, n. 3, e41708, set./dez. 2019. ISSN 1981-3694. DOI: http://dx.doi.org/10.5902/1981369441708. Disponível em: https://periodicos.ufsm.br/revistadireito/article/view/41708. Acesso em: 20 nov. 2021.

9 PARODO, Francesco. La protezione dei dati personali nell'integrazione europea. 2021. Tesi di Dottorato. Dottorato di Ricerca in Scienze giuridiche. Università degli Sudi di Cagliari. Cagliari, 2021. Disponível em: http://hdl.handle.net/11584/313092. Acesso em: 19 nov. 2021. 
ISSN 1981-3694

(DOI): $10.5902 / 1981369441636$

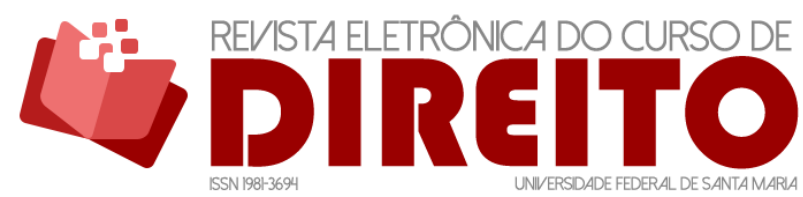

LEI GERAL DE PROTEÇÃO DE DADOS (LGPD) E AS COOPERATIVAS: IMPRESSÕES INICIAIS

José RAPHAEL BATISTA FreiRE LEILA ANDRESSA DISSENHA

até mesmo na coleta e tratamento de dados para fins de investigação e desenvolvimento processual criminal ${ }^{10}$.

Na América do Sul, Argentina (Ley de Protección de los Datos Personales, 2000), Chile (Ley de Protección de Datos de Caráter Personal, 1999), Colômbia (Ley Estatutaria $n^{\circ} 1581$ de 2012), Peru (Ley de Protección de De Atos Personales, 2011) e Uruguai (Ley de Proteccíon de Datos Personales y Accíon de Habeas Data, 2011) possuem legislação para a proteção de dados pessoais. No Brasil, a LGPD entrou integralmente em vigor em agosto de 2021.

0 artigo $6^{\circ}$ da Lei Geral de Proteção de Dados Pessoais elenca os princípios que deverão acompanhar o tratamento de dados pessoais: finalidade, adequação, necessidade, livre acesso, qualidade dos dados, transparência, segurança, prevenção, não discriminação e responsabilização e prestação de $\operatorname{contas}^{11}$. 0 caput do referido artigo de lei elenca o princípio da boa-fé e o da segurança, que são guias para o comportamento e tratamento de dados pessoais realizados pelas organizações ${ }^{12}$.

A Lei Geral de Proteção de Dados Pessoais conceitua o dado pessoal em seu artigo $5^{\circ}$, inciso I, como sendo "informação relacionada a pessoa natural identificada ou identificável"13. Da mesma forma como a lei brasileira, o GDPR elucida que os dados pessoais são relativos a qualquer informação sobre pessoa natural identificada ou identificável ${ }^{14}$. 0 titular dos dados pessoais, por sua vez, é a pessoa natural da qual é realizado o tratamento dos dados pessoais conforme inciso $\mathrm{V}$ do artigo $5^{\circ}$ da LGPD ${ }^{15}$.

Outro conceito detalhado pela Lei é dado pessoal sensível, aquele "sobre origem racial ou étnica, convicção religiosa, opinião política, filiação a sindicato ou a organização de caráter

\footnotetext{
${ }^{10}$ BACCARI, G.M.; CONTI, C. La corsa tecnologica tra Costituzione, codice di rito e norme sulla privacy: uno sguardo d'insieme. DIRITTO PENALE E PROCESSO, 6, p. 711-723, 2021. Disponível em: http://hdl.handle.net/11365/1151968. Acesso em: 20 nov. 2021.

${ }_{11}$ BRASIL. Lei ${ }^{\circ} 13.709$ de 14 de agosto de 2018. Dispõe sobre a proteção de dados pessoais. Diário Oficial da União. Brasília, DF. Disponível em: http://www.planalto.gov.br/ccivil_03/_ato20152018/2018/lei/L13709.htm. Acesso em: 27 mai. 2019.

12 SANTOS, Fabíola Meira de Almeida; TALIBA, Rita. Lei geral de proteção de dados no brasil e os possíveis impactos. Revista dos Tribunais, vol. 998, p. 225-239, dez., 2018.

13 BRASIL. Lei ${ }^{\circ} 13.709$ de 14 de agosto de 2018. Dispõe sobre a proteção de dados pessoais. Diário Oficial da União. Brasília, DF. Disponível em: http://www.planalto.gov.br/ccivil_03/_ato20152018/2018/lei/L13709.htm. Acesso em: 27 mai. 2019.

${ }_{14}$ VOSS, W. Gregory. European union data privacy law reform: General data protection regulation, privacy shield, and the right to delisting. The Business Lawyer, v. 72, n. 1, p. 221-234, 2016. Disponível em: https://hal.archives-ouvertes.fr/hal-02553947/file/TBL\%2072-1_10Voss.pdf.

${ }^{15}$ BRASIL. Lei ${ }^{\circ} 13.709$ de 14 de agosto de 2018. Dispõe sobre a proteção de dados pessoais. Diário Oficial da União. Brasília, DF. Disponível em: http://www.planalto.gov.br/ccivil_03/_ato20152018/2018/lei/L13709.htm. Acesso em: 27 mai. 2019.
} 
ISSN 1981-3694

(DOI): $10.5902 / 1981369441636$

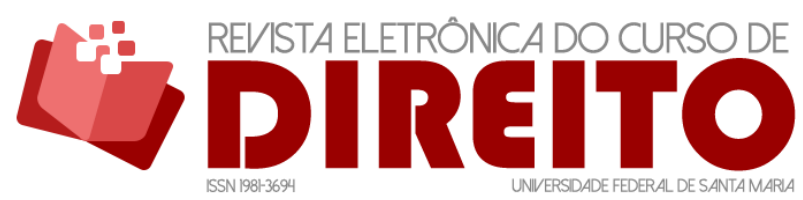

LEI GERAL DE PROTEÇÃO DE DADOS (LGPD) E AS COOPERATIVAS: IMPRESSÕES INICIAIS

José RAPHAEL BATISTA FreiRE LEILA ANDRESSA DISSENHA

religioso, filosófico ou político, dado referente à saúde ou à vida sexual, dado genético ou biométrico, quando vinculado a uma pessoa natural" (art. $5^{\circ}$, inciso II) ${ }^{16}$.

Em princípio, imagina-se que as pessoas físicas e jurídicas que realizam o tratamento de dados pessoais deverão colher autorização expressa de todos os titulares (empregados e clientes, por exemplo). Contudo, os incisos II a IX do artigo $7^{\circ}$ da Lei n. 13.709/18, menciona hipóteses em que é possível o tratamento de dados pessoais sem o consentimento do titular, como, por exemplo, para a proteção da vida, do crédito, assim como para a realização de estudos de pesquisa e para a tutela da saúde.

Nesse contexto, impende salientar que a Lei Geral de Proteção de Dados Pessoais não vem como um instrumento para que o titular sempre forneça seu consentimento para o tratamento de seus dados, mas, sobretudo, para regular as hipóteses em que é possível o tratamento dos dados sem o consentimento do usuário ${ }^{17}$.

Conforme artigos 37 e 39 da Lei Geral de Proteção de Dados Pessoais, os responsáveis pelo tratamento de dados pessoais são o operador e o controlador. Em breve explicação, o operador realiza o tratamento dos dados pessoais, ao passo que o controlador toma as decisões e fornece informações ao operador para que possa ser realizado o tratamento dos dados ${ }^{18}$.

Impende salientar, nesse contexto, que algumas organizações irão precisar nomear o Encarregado pelo Tratamento de Dados Pessoais, consoante disciplina o artigo 41 da Lei 13.709/18. Entretanto, como não há expressa previsão na LGPD sobre quais organizações deverão nomear o encarregado, será necessária orientação e regulamentação pela Autoridade Nacional de Proteção de Dados ${ }^{19}$.

\footnotetext{
${ }^{16}$ Como explicam RAMOS et. al.: "A LGPD brasileira, seguindo a trilha da legislação europeia, também entende os dados de saúde como uma categoria especial, sendo considerados dados pessoais sensíveis. Entendendo que dado pessoal sensível é o dado pessoal sobre origem racial ou étnica, convicção religiosa, opinião política, filiação a sindicato ou a organização de caráter religioso, filosófico ou político, dado referente à saúde ou à vida sexual, dado genético ou biométrico, quando vinculado a uma pessoa natural." (RAMOS, E. M. B. et al. Questões éticas e perspectiva jurídica da proteção de dados. Cadernos Ibero-Americanos de Direito Sanitário, [S. I.], v. 10, n. 3, p. 172-190, 2021. DOI: https://doi.org/10.17566/ciads.v10i3.796. Disponível em: https://www.cadernos.prodisa.fiocruz.br/index.php/cadernos/article/view/796. Acesso em: 20 nov. 2021).

17 LIMA, Caio César Carvalho. Objeto, aplicação material e aplicação territorial. In: BLUM, Renato Opice; MALDONADO, Viviane Nóbrega (coord.). Comentários ao GDPR: Regulamento Geral de Proteção de Dados da União Europeia. São Paulo: Thomson Reuters. Brasil, 2018.

${ }^{18}$ SANTOS, Fabíola Meira de Almeida; TALIBA, Rita. Lei geral de proteção de dados no brasil e os possíveis impactos. Revista dos Tribunais, vol. 998, p. 225-239, dez., 2018.

19 BRUNO, Marcos Gomes da Silva. In: BLUM, Renato Opice; MALDONADO, Viviane Nóbrega (coord.). Lei Geral de Proteção de Dados comentada. São Paulo: Thomson Reuters. Brasil, 2019.
} 
ISSN 1981-3694

(DOI): $10.5902 / 1981369441636$

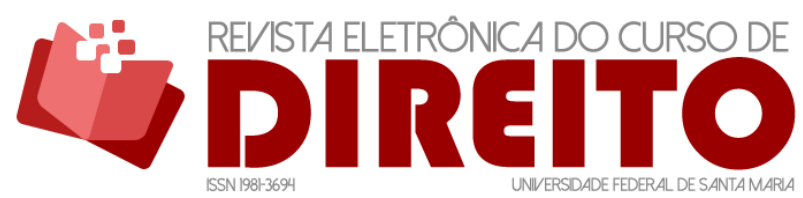

LEI GERAL DE PROTEÇÃO DE DADOS (LGPD) E AS COOPERATIVAS: IMPRESSÕES INICIAIS

José RAPHAEl BATISTA FREIRE LEILA ANDRESSA DISSENHA

Destaca-se, ademais, que até mesmo a eliminação dos dados pessoais é considerada, pela LGPD, uma forma de tratamento de dados pessoais, de modo que a ele deve ser aplicados todos os cuidados, assim como os princípios da legislação, para que não haja nenhuma afronta à legislação quando da eliminação dos dados; as formas de eliminação estão previstas no artigo 16 da LGPD. Rememore-se que a Lei Geral de Proteção de Dados Pessoais é aplicada tanto para dados pessoais físicos quanto digitais (art. $1^{\circ}$, Lei 13.709/2018).

Um dos pontos regulamentados pela LGPD é a transferência internacional de dados, conceituada como a "transferência de dados pessoais para país estrangeiro ou organismo internacional do qual o país seja membro" (art. 5, inciso XV, da Lei 13.709/2018). Portanto, considerando que dados pessoais são "toda informação relacionada a pessoa natural identificada ou identificável” (art. $5^{\circ}$, inciso I, da Lei 13.709/2018), a transferência de dados entre países pode ser verificada da forma mais ampla possível.

Conforme o artigo 52 da Lei Geral de Proteção de Dados, os agentes de tratamento ficam sujeitos às sanções administrativas, que abarcam desde a advertência (art. 52, inciso I) até a imposição de multa simples de até $2 \%$ (dois por cento) do faturamento da pessoa jurídica (art. 52, inciso II). Ademais, a aplicação das referidas sanções não substitui eventual responsabilização civil ou criminal por parte da pessoa jurídica que infringir a Lei Geral de Proteção de Dados (art. 52, parágrafo $2^{\circ}$ ).

As punições para o descumprimento da Lei são, portanto, bastante severas, merecendo, assim, a atenção dos gestores. De outra vertente, é possível vislumbrar que uma política adequada de proteção de dados pela cooperativa pode fornecer mais segurança aos seus cooperados, de modo a aumentar a confiabilidade da organização.

\section{SOBRE O COOPERATIVISMO}

As Cooperativas surgiram em 1844, na cidade de Rochdale, quando vinte e oito tecelões fundaram uma cooperativa de consumo, objetivando negociar em dinheiro a preços mais baixos em benefício de seus associados ${ }^{20}$. Saliente-se que, à época, estava-se realizando a transição da sociedade rural para a sociedade industrial, onde os trabalhadores estavam sendo submetidos a

20 GARRAT, Roy. Rochdale Equitable Pioneers Society. In: DULFER, Eberhard (ed.). International Handbook of Cooperative Organizations. Germany: Vandenhoeck \& Ruprecht in Göttingen. 1994. 
ISSN 1981-3694

(DOI): $10.5902 / 1981369441636$

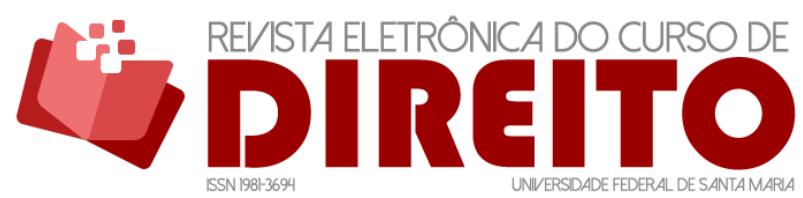

LEI GERAL DE PROTEÇÃO DE DADOS (LGPD) E AS COOPERATIVAS: IMPRESSÕES INICIAIS

José RAPHAEL BATISTA FreiRE LEILA ANDRESSA DISSENHA

uma jornada de dezessete horas diárias, passando fome e não contando com nenhum benefício social, de modo a vivenciar a verdadeira miséria ${ }^{21}$.

Em 27 de outubro de 1889 foi instalada a primeira organização brasileira com a denominação Cooperativa em Ouro Preto - Minas Gerias; somente em 1902, em Nova Petrópolis Rio Grande do Sul, foi fundada a primeira cooperativa de crédito brasileira ${ }^{22}$. Ademais, no Brasil, ainda se tem notícias de criação de cooperativa de crédito inaugurada em 1906 no município de Lajeado - Rio Grande do Sul ${ }^{23}$.

As sociedades cooperativas são regidas por sete princípios cooperativistas que foram apresentados pelos próprios Pioneiros de Rochdale: 1) adesão livre; 2) administração democrática; 3) retorno na proporção das compras; 4) juro limitado ao capital; 5) neutralidade política e religiosa; 6) pagamento em dinheiro à vista; 7) fomento da educação cooperativa ${ }^{24}$. Da mesma forma, mencionados princípios encontram-se indicados no artigo $4^{\circ}$ da Lei do Cooperativismo Brasileira (Lei $n^{\circ}$. 5.764/71). Anote-se, por oportuno, que os Princípios de Rochdale foram acolhidos pela $\mathrm{ACl}$ (Aliança das Cooperativas Internacional) no Congresso em Londres de $1934^{25}$.

As Cooperativas são sociedades de pessoas, regulamentadas, de forma geral, pela Lei $\mathrm{n}^{\circ}$. 5.764/71 e por algumas leis específicas conforme o ramo, como é o caso das Cooperativas de Crédito, sujeitas à Lei Complementar $n^{\circ}$. 130/2009. Nessa conjuntura, a cooperativa é uma organização em que se busca fins econômicos, sociais e educativos em comum, por meio de uma empresa comercial ${ }^{26}$.

As organizações cooperativas, criadas inicialmente como organização de consumo, consoante sobredito, possuem, atualmente, sete ramos, de acordo com a Resolução n. 56/2019 da Organização das Cooperativas Brasileiras $(O C B)^{27}$, quais sejam: agropecuário, consumo,

21 BIALOSKORSKI NETO, Sigismundo. Aspectos Econômicos das Cooperativas. Belo Horizonte: Mandamentos. 2006.

22 PINHEIRO, Marcos Antonio Henrique. Cooperativas de crédito: história da evolução normativa no Brasil. 6. ed. Brasília: Banco Central do Brasil. 2008. Disponível em: https://www.bcb.gov.br/content/publicacoes/Documents/outras_pub_alfa/livro_cooperativas_credito.pd f. Acesso em: 11 dez. 2019.

$\overline{2}_{3}$ PINHEIRO, Marcos Antonio Henrique. Cooperativas de crédito: história da evolução normativa no Brasil. 6. ed. Brasília: Banco Central do Brasil. 2008. Disponível em: https://www.bcb.gov.br/content/publicacoes/Documents/outras_pub_alfa/livro_cooperativas_credito.pd f. Acesso em: 11 dez. 2019.

${ }^{24}$ FRANKE, Walmor. Direito das sociedades cooperativas: direito cooperativo. São Paulo: Saraiva. 1973.

${ }^{25}$ FRANKE, Walmor. Direito das sociedades cooperativas: direito cooperativo. São Paulo: Saraiva. 1973.

${ }^{26} \mathrm{GIDE}$, Charles. El cooperativismo. Buenos Aires: INTERCOOP- 48. 1974

27 RAMOS do cooperativismo. Sistema OCB. Disponível em: https://somoscooperativismo.coop.br/publicacao/57/ramos-do-cooperativismo. Acesso em: 11 de dezembro de 2019. 
ISSN 1981-3694

(DOI): $10.5902 / 1981369441636$

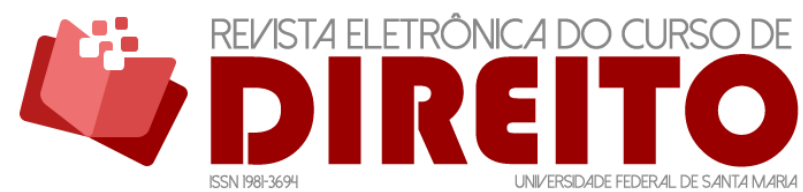

LEI GERAL DE PROTEÇÃO DE DADOS (LGPD) E AS COOPERATIVAS: IMPRESSÕES INICIAIS

José RAPHAEL BATISTA FREIRE LEILA ANDRESSA DISSENHA

crédito, infraestrutura, trabalho, produção de bens e serviços, saúde e transporte. Anote-se, por oportuno, que os ramos passaram por reestruturação no ano corrente, de modo que até então existiam treze ramos.

A importância econômica das Cooperativas é inquestionável, exercendo um papel crucial no desenvolvimento econômico de inúmeros Municípios brasileiros. Na observância de seus princípios, legalmente prestigiados e reconhecidos internacionalmente pela Aliança Cooperativa Internacional $(\mathrm{ACl}, 1995)$, as Cooperativas ganham notoriedade, também, por sua contribuição social, ao gerar empregos diretos e indiretos, oportunidade de renda e crescimento pessoal, além de oferecer serviços e produtos de qualidade, impactando toda a comunidade que as cerca. ${ }^{28}$

Para que se vislumbre a importância do sistema cooperativismo mundial, contemporaneamente existem 1,2 bilhão de cooperados, 280 milhões de colaboradores e 3 milhões de cooperativas. O maior ramo cooperativista mundial é o agropecuário, contando com 1,2 milhão de cooperativas no mundo. Ademais, as 300 (trezentas) maiores cooperativas do mundo tem um faturamento de US\$ 2,1 trilhões $^{29}$.

Nos últimos 8 anos, a quantidade de empregos gerados pelas cooperativas aumentou 43\% (quarenta e três por cento), fato que denota a grande importância das organizações no mercado nacional. Não obstante, em 2018 o número de cooperativas no Brasil ativas é de 6.828 (seis mil oitocentos e vinte e oito), alcançando $\mathrm{R} \$ 351,4$ bilhões de ativos, $\mathrm{R} \$ 259,9$ bilhões de ingresso e receitas brutas, R\$ 7,6 bilhões de sobras do Exercício de 2018 e R\$ 40,2 bilhões de capital social. Os principais ramos do cooperativismo, com os quais o cidadão brasileiro mais se relaciona, são a saúde (41\%), transporte de carga ou táxi (40\%), consumo (35\%) e crédito $(34 \%)^{30}$.

Em relação ao cooperativismo brasileiro, importante pontuar que 34\% (trinta e quatro por cento) das cooperativas brasileiras importam e exportam commodities, sendo que $48 \%$ (quarenta e oito por cento) das cooperativas apenas possuem a exportação ${ }^{31}$. Isso demonstra que, a priori, mais de $80 \%$ (oitenta por cento) das organizações cooperativas brasileiras precisam

\footnotetext{
${ }^{28}$ Exemplo disso são os inúmeros casos relatados pelo movimento Somos Coop, com destaque especial para o impacto da Cooperativa de Crédito Sicoob Saromcredi em relação ao Município de São Roque de Minas, MG. SISTEMA OCB. Somos Coop, 2019. Página Inicial. Disponível em: https://www.somos.coop.br/. Acesso em: 21 mai. 2019.

29 NÚMEROS do cooperativismo. Sistema OCB, 2019. Disponível em: https://www.ocb.org.br/numeros. Acesso em: 10 dez. 19.

30 NÚMEROS do cooperativismo. Sistema OCB, 2019. Disponível em: https://www.ocb.org.br/numeros. Acesso em: 10 dez. 19.

31 NÚMEROS do cooperativismo. Sistema OCB, 2019. Disponível em: https://www.ocb.org.br/numeros. Acesso em: 10 dez. 19.
} 
ISSN 1981-3694

(DOI): $10.5902 / 1981369441636$

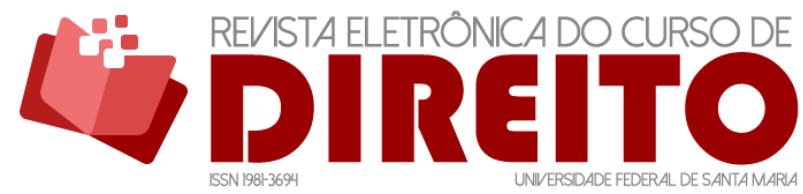

LEI GERAL DE PROTEÇÃO DE DADOS (LGPD) E AS COOPERATIVAS: IMPRESSÕES INICIAIS

José RAPHAEL BATISTA FREIRE LEILA ANDRESSA DISSENHA

se atentar tanto para a Lei Geral de Proteção de dados brasileira quanto para verificar se o país com que mantém negócios possui uma proteção adequada aos dados de todos os stakeholders.

Como pessoas jurídicas que são, as Cooperativas formam uma imensa rede de pessoas e negócios. Clientes, colaboradores, terceirizados, fornecedores, parceiros e profissionais pessoas físicas são apenas alguns dos membros desta rede cujos dados pessoais terão impacto direto pela disciplina da LGPD. Assim, o impacto que os parâmetros da LGPD, ainda que sem regulamentação específica, pode causar em cada ramo das cooperativas é, definitivamente, algo a se considerar.

\section{DESAFIOS DE IMPLEMENTAÇÃO PARA ADEQUAÇÃO DAS COOPERATIVAS À LEI GERAL DE PROTEÇÃO DE DADOS}

Contextualizado o problema, tenta-se, a partir daqui, com base na letra da lei e no parco material bibliográfico já desenvolvido a respeito do tema, apontar em que situações a proteção de dados poderá fazer-se mais necessária no cotidiano das Cooperativas, respeitadas as particularidades de cada ramo de atuação.

$\mathrm{Na}$ sua atuação nacional, as cooperativas trabalham com dados pessoais diariamente, especialmente de seus cooperados - e isso nas mais diversas formas: as cooperativas do ramo agropecuário manejam a matrícula e dados da plantação ou dos animais do cooperado; as de saúde, manejam informações sensíveis, como a autorização de exames e consultas; as de crédito, lidam com dados financeiros do cooperado, por exemplo.

Às cooperativas que se dedicam à exportação, em especial, aos países da União Europeia (UE), vale mencionar que o artigo $3^{\circ}$, item 1, da GDPR (General Data Protection Regulation), disciplina que o regulamento se aplica independentemente de o tratamento dos dados ocorrer dentro ou fora da UE - o que significa que, caso a cooperativa pratique atos de exportação para qualquer país vinculado à União Europeia, deverá se adequar ao Regulamento.

Sendo assim, é necessário que as cooperativas (em especial às do ramo agropecuário) que transacionam com os países submetidos ao GDPR igualmente devem estar adequadas ao Regulamento Europeu, não somente adequadas à legislação brasileira - Lei Geral de Proteção de Dados Pessoais $^{32}$. Caso não haja a adequação, a cooperativa poderá sofrer penalidades de acordo com as regras de cada Estado-Membro (art. 84 do GDPR).

32 FREIRE, José Raphael Batista. A transparência do programa de proteção de dados pessoais nas cooperativas agroindustriais do Estado do Paraná sob as perspectivas jurídica e institucional. 
ISSN 1981-3694

(DOI): $10.5902 / 1981369441636$

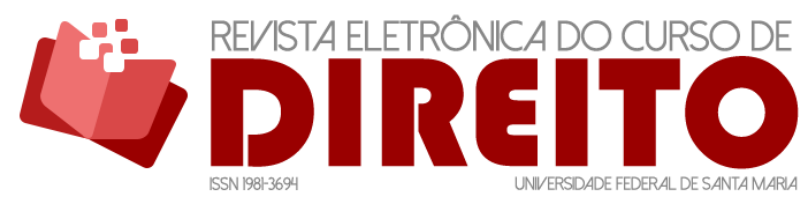

LEI GERAL DE PROTEÇÃO DE DADOS (LGPD) E AS COOPERATIVAS: IMPRESSÕES INICIAIS

José RAPHAEL BATISTA FreiRE LEILA ANDRESSA DISSENHA

Outrossim, além de se adequar aos preceitos do Regulamento Europeu, às cooperativas que transacionam com outras países, é imprescindível observar a transferência internacional de dados, prevista no artigo 33 da Lei Geral de Proteção de Dados Pessoais ${ }^{33}$. Adicionalmente, pontue-se que a transferência internacional de dados pessoais é vista como exceção, somente sendo possível nas hipóteses taxativas do mencionado artigo 33 da Lei $n^{\circ}$. 13.709/18 ${ }^{34}$. Isso significa que as cooperativas que exportam ou mantém qualquer tipo de relação com organizações situadas em outro país deverá, antes de prosseguir com o relacionamento, averiguar se o país que está localizado a organização possui legislação adequada para o tratamento de dados pessoais. Pontue-se, ademais, que o nível de proteção de dados pessoais do outro país será validado pela Autoridade Nacional de Proteção de Dados, conforme artigo 34 da LGPD $^{35}$.

Por outro lado, às cooperativas de crédito, aplica-se essencialmente o disciplinado no inciso $X$ do artigo $7^{\circ}$ da Lei Geral de Proteção de Dados, onde se possibilita o tratamento de dados do titular para a "proteção do crédito". Referido dispositivo legal deverá ser interpretado de forma sistêmica e conjunta com as demais legislações acerca do setor de crédito, o que possibilitará maior garantia ao titular dos dados ${ }^{36}$. Explica-se que, no caso das cooperativas de crédito, o titular dos dados será o próprio cooperado.

Nesse aspecto, o parágrafo $4^{\circ}$ do artigo 11 da LGPD, estabelece que é "vedada a comunicação ou o uso compartilhado entre controladores de dados pessoais sensíveis referentes à saúde, com o objetivo de obter vantagem econômica"37. Entretanto, há duas exceções (ou seja, quando é possível o compartilhamento de dados sensíveis atinentes à saúde): consentimento do titular e para a prestação adequada dos serviços de saúde suplementar

Dissertação (Mestrado em Gestão de Cooperativas). Pontifícia Universidade Católica do Paraná. Curitiba, 2021.

33 FREIRE, José Raphael Batista. A transparência do programa de proteção de dados pessoais nas cooperativas agroindustriais do Estado do Paraná sob as perspectivas jurídica e institucional. Dissertação (Mestrado em Gestão de Cooperativas). Pontifícia Universidade Católica do Paraná. Curitiba, 2021.

34 CHAVES, Luis Fernando Prado. In: BLUM, Renato Opice; MALDONADO, Viviane Nóbrega (coord.). Lei Geral de Proteção de Dados comentada. São Paulo: Thomson Reuters. Brasil, 2019.

35 FREIRE, José Raphael Batista. A transparência do programa de proteção de dados pessoais nas cooperativas agroindustriais do Estado do Paraná sob as perspectivas jurídica e institucional. Dissertação (Mestrado em Gestão de Cooperativas). Pontifícia Universidade Católica do Paraná. Curitiba, 2021.

${ }^{36}$ MENDES, Laura Schertel; DONEDA, Danilo. Reflexões iniciais sobre a nova lei geral de proteção de dados. Revista de Direito do Consumidor, vol. 120, p. 469-483, nov./dez. 2018. p. 3.

${ }^{37}$ BRASIL. Lei $\mathrm{n}^{\circ} 13.709$ de 14 de agosto de 2018. Dispõe sobre a proteção de dados pessoais. Diário Oficial da União. Brasília, DF. Disponível em: http://www.planalto.gov.br/ccivil_03/_ato20152018/2018/lei/L13709.htm. Acesso em: 27 mai. 2019. 
ISSN 1981-3694

(DOI): $10.5902 / 1981369441636$

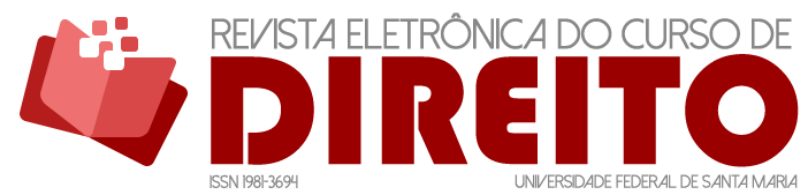

LEI GERAL DE PROTEÇ̃̃O DE DADOS (LGPD) E AS COOPERATIVAS: IMPRESSÕES INICIAIS

JOSÉ RAPHAEL BATISTA FREIRE LEILA ANDRESSA DISSENHA

(incisos I e II do parágrafo $4^{\circ}$ do artigo 11 da Lei 13.709/18). Por consequência, visualiza-se uma necessidade de adequação das cooperativas que possuem essa expertise, pois o compartilhamento de dados em que há apresentação de dados da saúde do portador possuem especificidades no seu tratamento.

No entanto, é possível questionar a necessidade de pleitear o consentimento do titular (quando este for o cooperado) quando o tratamento de dados pessoais se referir a atos cooperados ou atos que de qualquer forma envolva a figura do cooperado. Rememore-se que ao cooperado é o principal ativo da cooperativa e esta somente existe para agir em função dele. Com efeito, a imprescindibilidade de coleta do consentimento para atos cooperados ou atos praticados pela cooperativa em benefício do seu associado, pode inviabilizar a atividade cooperada $^{38}$. Vale salientar, novamente, que a LGPD foi possui uma espécie de "cláusula geral" para regular o tratamento de dados sem o consentimento do titular, prevista no inciso IX do artigo $7^{\circ}$ da Lei $13.709 / 18^{39}$.

Para que a cooperativa possa tratar os dados pessoais do cooperado - ou de qualquer outro dado pessoal que tenha em seu banco de dados - deverá o fazer por meio de um controlador e operador de dados, que são os agentes de tratamento de dados - a quem incumbe, também, a elaboração do Relatório de Impacto à Proteção de Dados Pessoais ${ }^{40}$. Nesse sentido, a revisão dos contratos pelas cooperativas - seja com cooperados ou não - é medida adequada para que se possa adequar aos ditames da Lei Geral de Proteção de Dados, essencialmente no que se refere ao tratamento dos dados pessoais, de forma a se pautar pela transparência, proporcionalidade e necessidade ${ }^{41}$.

A Cooperativa, seja qual for o ramo de atuação, pode ser empregadora (e, normalmente, o é); nesse caso, a organização precisa estabelecer políticas de proteção de dados pessoais dos seus empregados. Se há preocupações na adaptação do cotidiano da Cooperativa à LGPD em seu trato diário com cooperados e parceiros nacionais e internacionais de negócios, na relação com seus empregados essa preocupação deve ser ainda maior. Sintetiza-se no sentido de

38 FREIRE, José Raphael Batista. A transparência do programa de proteção de dados pessoais nas cooperativas agroindustriais do Estado do Paraná sob as perspectivas jurídica e institucional. Dissertação (Mestrado em Gestão de Cooperativas). Pontifícia Universidade Católica do Paraná. Curitiba, 2021.

${ }^{39}$ MENDES, Laura Schertel; DONEDA, Danilo. Reflexões iniciais sobre a nova lei geral de proteção de dados. Revista de Direito do Consumidor, vol. 120/2018, p. 469-483, nov./dez. 2018. p. 3.

40 CRESPO, Danilo Leme; RIBEIRO FILHO, Dalmo. A evolução legislativa brasileira sobre a proteção de dados pessoais: a importância da promulgação da lei geral de proteção de dados pessoais. Revista de Direito Privado, vol. 98, p. 161-186, mar./abr., 2019. p. 15.

41 SANTOS, Fabíola Meira de Almeida; TALIBA, Rita. Lei geral de proteção de dados no brasil e os possíveis impactos. Revista dos Tribunais, vol. 998, p. 225-239, dez., 2018. p. 3. 
ISSN 1981-3694

(DOI): $10.5902 / 1981369441636$

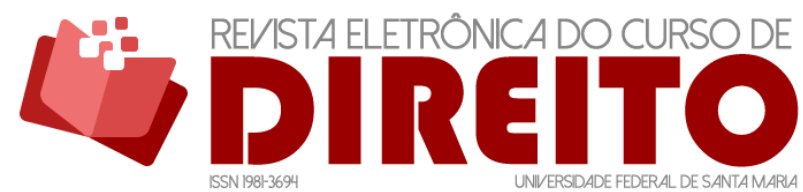

LEI GERAL DE PROTEÇÃO DE DADOS (LGPD) E AS COOPERATIVAS: IMPRESSÕES INICIAIS

José RAPHAEL BATISTA FreiRE LEILA ANDRESSA DISSENHA

que o tratamento adequado dos dados do empregado se inicia no processo seletivo, ou seja, antes mesmo de ser efetivado ${ }^{42}$.

Nesse contexto, por muitos anos, dados pessoais foram manipulados por empregadores e seus departamentos de recursos humanos sem maiores cuidados. Desde o processo de recrutamento até o momento da admissão, múltiplos litígios revelam o descuido com que informações pessoais foram tratadas, por décadas.

Apenas a título de exemplo - e restrito a casos individuais - a quarta turma do Tribunal Regional do Trabalho da $2^{\text {a }}$. Região, no processo RO 00657.2000.064.02.00-3, condenou a empregadora a indenizar ex-colaborador por divulgar o motivo de sua rescisão contratual por justa causa (2005); ${ }^{43}$ no processo RR-291-62.2013.5.04.0404, o Tribunal Superior do Trabalho condenou a empregadora por divulgar resultados de exame toxicológico de um empregado aos demais empregados $(2014) ;^{44}$ e, mais recentemente (2018), pelo processo RR-11855.2013.5.09.0127, o TST condenou a empregadora por vazar dados salariais de empregado em uma rede social. ${ }^{45}$ Visualiza-se, nessa conjuntura, que houve condenação pela divulgação dos dados pessoais dos empregados antes mesmo de a LGPD (Lei Geral de Proteção de Dados Pessoais) entrar em vigor.

De fato, a própria Lei, que entrou integralmente em vigor em agosto de 2021, recomenda que os cuidados tenham início com o estabelecer de boas práticas, fixação de diretrizes de governança para garantir o acesso controlado e autorizado aos dados pessoais, para fins permitidos por lei e apenas durante o tempo necessário.

Quando se indaga quais devem ser as maiores preocupações da Cooperativa quanto ao zelo com os dados de seus empregados, o ponto de ponto de partida, parece ser, justamente, as inúmeras condenações anteriores envolvendo o descuido com tais dados e os parâmetros da nova lei.

\footnotetext{
42 RAMOS, Lara Castro Padilha; GOMES, Ana Virgínia Moreira. Lei geral de dados pessoais e seus reflexos nas ralações de trabalho. Scientia luris, Londrina, v. 23, n. 2, p. 127-146, jul. 2019. DOI: 10.5433/21788189.2019v23n2p127. ISSN: 2178-8189.

43 DIVULGAR motivo de demissão gera dano moral. Consultor Jurídico, 2005. Disponível em: https://www.conjur.com.br/2005-jun-06/divulgar_motivo_demissao_gera_dano_moral. Acesso em: 20 de abril de 2019.

44 STOEVER, Carlos. Empresa é condenada por divulgar exame toxicológico de funcionário. Consultor Trabalhista. Disponível em: https://consultortrabalhista.com/noticias/empresa-e-condenada-pordivulgar-exame-toxicologico-de-funcionario/. Acesso: em 07 de abril de 2019.

45 EMPRESA indenizará funcionário que teve dados vazados na internet. Consultor Jurídico, 2018. Disponível em: https://www.conjur.com.br/2018-jan-10/empresa-indenizara-funcionario-teve-dadosvazados-internet. Acesso: em 20 de abril de 2019.
} 
ISSN 1981-3694

(DOI): $10.5902 / 1981369441636$

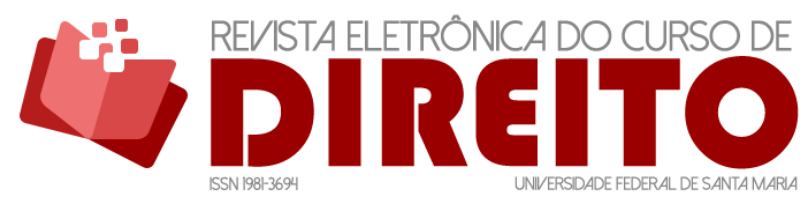

LEI GERAL DE PROTEÇ̃̃O DE DADOS (LGPD) E AS COOPERATIVAS: IMPRESSÕES INICIAIS

José RAPHAEL BATISTA FREIRE LEILA ANDRESSA DISSENHA

Diante deste questionamento, norteando-se pelos critérios acima, indica-se três posicionamentos, de indispensável análise, para que se possa desenvolver uma estratégia apurada para evitar vazamentos e incidentes com dados pessoais:

I - Investimento em tecnologia. As informações que cercam um empreendimento possuem valor considerável e precisam ser manipuladas e armazenadas de forma segura. Gastos com ferramentas e profissionais habilitados que possam garantir que os dados pessoais dos titulares, incluindo os de seus empregados, sejam protegidos e manipulados adequadamente é um verdadeiro e válido investimento.

II - Treinamento e transparência. Não é de hoje que empreendimentos têm investido na formação de programas de Compliance e elaboração de códigos de conduta a fim de espelhar nas atitudes cotidianas a ética exigida pela legislação e pela sociedade. Embora este investimento seja de absoluta necessidade, inclusive quanto à proteção e tratamento de dados pessoais, ela só será eficaz quando as pessoas forem instruídas a observá-la em todas as etapas do seu cotidiano: de nada adianta investir em tecnologia de ponta para proteção de dados se senhas forem compartilhadas por descaso se seus portadores, por exemplo. Da mesma forma, o titular precisa saber como seus dados são tratados, com absoluta transparência, até para que possa ter plena ciência dos efeitos de sua aquiescência na utilização de suas informações nas rotinas trabalhistas da empregadora, por exemplo.

III - Cuidados maiores com dados sensíveis. O empregado que comprovou sua candidatura à dirigente sindical para fins de marco inicial de garantia no emprego; a empregada que trouxe à empresa documentação sobre sua união estável, para formalização de dependentes perante o INSS; e o aprendiz que declara não poder fazer horas de trabalho aos sábados em razão das práticas de sua religião: em todas estes pequenos e corriqueiros exemplos, há algo em comum: o fornecimento de dados sensíveis - ou seja, de dados que exprimem sua opção sexual, suas convicções religiosas, posicionamentos políticos, por exemplo. Nestes casos, o cuidado deve ser ainda maior quanto às pessoas que irão manipular e à forma como serão armazenadas estas informações.

Constata-se, assim, que toda cooperativa deverá se amoldar à Lei Geral de Proteção de Dados, podendo sofrer sanções em caso de não adequação à Lei 13.709/2018. Contudo, a adequação das cooperativas à LGPD deverá se pautar como forma de proteger os dados pessoais, principalmente, de seus cooperados. 
ISSN 1981-3694

(DOI): $10.5902 / 1981369441636$

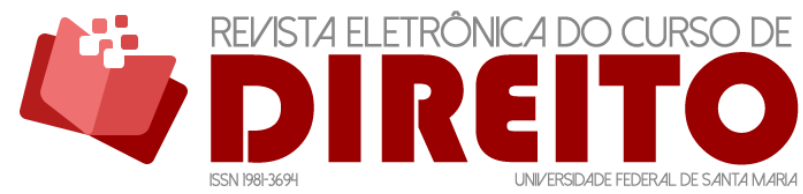

LEI GERAL DE PROTEÇÃO DE DADOS (LGPD) E AS COOPERATIVAS: IMPRESSÕES INICIAIS

José RAPHAEL BATISTA FREIRE LEILA ANDRESSA DISSENHA

É fundamental recordar que, seja na Europa, seja no Brasil, a proteção de dados transcende a questão tecnológica e os meios digitais ${ }^{46}$ - tão evidenciados em tempos pandêmicos, como o zelo pelos dados na realização de assembleias digitais. Como exemplificado acima, mais que a implementação dos mecanismos que a Lei requer, os cuidados se impõem às rotinas e processos do cotidiano das organizações, dentre elas, às das Cooperativas.

\section{CONCLUSÃO}

O presente artigo contemplou a edição da Lei Geral de Proteção de Dados, que foi aprovada em 14 de agosto de 2018 e entrou em vigor plenamente no dia primeiro de agosto de 2021. Não se teve a intenção de esgotar o tema, pelo contrário, apenas salientando alguns desafios de implementação da nova legislação que podem impactar profundamente as organizações cooperativas.

Isso se dá pelo fato de que as cooperativas devem possuir práticas adequadas de proteção de dados pessoais, como forma de proteger a privacidade de todas as pessoas físicas que praticam atos com as cooperativas (empregados, usuários, cooperados), inclusive quando efetuam a transferência internacional de dados, ou seja, consoante citado, muito comum para as cooperativas do ramo agropecuário que exportam.

Ademais, destacou-se especialmente que as cooperativas deverão oferecer práticas adequadas de proteção de dados como forma de gerar maior segurança aos seus cooperados, pois a organização possui comando sobre referidos dados. Não obstante, pontuou-se que há penas severas para as organizações que tiverem vazamento de dados, nela estando incluídas as cooperativas.

Finalmente, a LGPD não vem como uma legislação para impedir o uso dos dados pessoais por parte das cooperativas, pelo contrário, vem apenas para regulamentar a forma como serão tratados os dados dos titulares pelas organizações, de modo a fornecer maior segurança aos usuários, cooperados, empregados e todas as pessoas que ofertam seus dados a uma organização.

\footnotetext{
${ }^{46}$ BARBOSA, J. S. et al. A proteção de dados e segurança da informação na pandemia COVID-19: contexto nacional. Research, Society and Development, [S. I.], v. 10, n. 2, p. e40510212557, 2021. DOI: 10.33448/rsd-v10i2.12557. Disponível em: https://rsdjournal.org/index.php/rsd/article/view/12557. Acesso em: 20 nov. 2021.
} 
ISSN 1981-3694

(DOI): $10.5902 / 1981369441636$

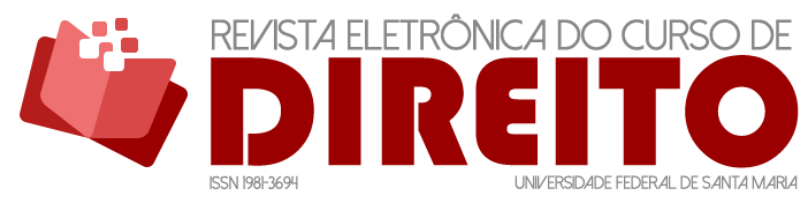

LEI GERAL DE PROTEÇÃO DE DADOS (LGPD) E AS COOPERATIVAS: IMPRESSÕES INICIAIS

José RAPHAEL BATISTA FreiRE LEILA ANDRESSA DISSENHA

\section{REFERÊNCIAS}

BACCARI, G.M.; CONTI, C. La corsa tecnologica tra Costituzione, codice di rito e norme sulla privacy: uno sguardo d'insieme. DIRITTO PENALE E PROCESSO, 6, p. 711-723, 2021. Disponível em: http://hdl.handle.net/11365/1151968. Acesso em: 20 nov. 2021.

BARBOSA, J. S. et al. A proteção de dados e segurança da informação na pandemia COVID-19: contexto nacional. Research, Society and Development, [S. l.], v. 10, n. 2, p. e40510212557, 2021. DOI: $10.33448 /$ rsd-v10i2.12557. Disponível em:

https://rsdjournal.org/index.php/rsd/article/view/12557. Acesso em: 20 nov. 2021.

BIALOSKORSKI NETO, Sigismundo. Aspectos Econômicos das Cooperativas. Belo Horizonte: Mandamentos. 2006.

BRASIL. Constituição Federal. Brasília: Senado Federal, 1988. Disponível em: http://www.planalto.gov.br/ccivil_03/constituicao/constituicao.htm. Acesso em: 1 dez. 2019.

BRASIL. Lei n 5.764 de 16 de dezembro de 1971. Define a Política Nacional de Cooperativismo, institui o regime jurídico das sociedades cooperativas, e dá outras providências. Diário Oficial da União. Brasília, DF. Disponível em: http://www.planalto.gov.br/ccivil_03/LEIS/L5764.HTM. Acesso em: 11 dez. 2019.

BRASIL. Lei $n^{\circ} 13.709$ de 14 de agosto de 2018. Dispõe sobre a proteção de dados pessoais. Diário Oficial da União. Brasília, DF. Disponível em:

http://www.planalto.gov.br/ccivil_03/_ato2015-2018/2018/lei/L13709.htm. Acesso em: 27 mai. 2019.

BRUNO, Marcos Gomes da Silva. In: BLUM, Renato Opice; MALDONADO, Viviane Nóbrega (coord.). Lei Geral de Proteção de Dados comentada. São Paulo: Thomson Reuters. Brasil, 2019.

CHAVES, Luis Fernando Prado. In: BLUM, Renato Opice; MALDONADO, Viviane Nóbrega (coord.). Lei Geral de Proteção de Dados comentada. São Paulo: Thomson Reuters. Brasil, 2019.

CRESPO, Danilo Leme; RIBEIRO FILHO, Dalmo. A evolução legislativa brasileira sobre a proteção de dados pessoais: a importância da promulgação da lei geral de proteção de dados pessoais. Revista de Direito Privado, vol. 98, p. 161-186, mar./abr., 2019.

DIVULGAR motivo de demissão gera dano moral. Consultor Jurídico, 2005. Disponível em: https://www.conjur.com.br/2005-jun-06/divulgar_motivo_demissao_gera_dano_moral. Acesso em: 20 de abril de 2019.

EMPRESA indenizará funcionário que teve dados vazados na internet. Consultor Jurídico, 2018. Disponível em: https: //www.conjur.com.br/2018-jan-10/empresa-indenizara-funcionario-tevedados-vazados-internet. Acesso: em 20 de abril de 2019.

FIORINELLI, G. La moltiplicazione dei garanti nel settore della tutela dei dati personali: riflessi penalistici del GDPR. Rivista Trimestrale di Diritto Penale Contemporaneo, 2, 2019. ISSN 22407618. Disponível em: http://hdl.handle.net/2318/1719754. Acesso em: 19 nov. 2021. 
ISSN 1981-3694

(DOI): $10.5902 / 1981369441636$

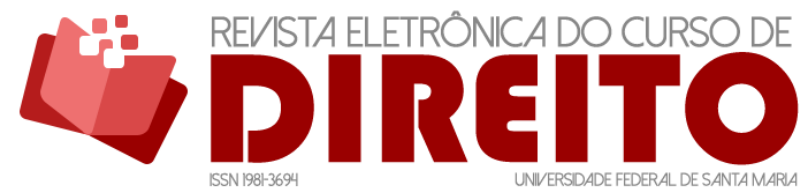

LEI GERAL DE PROTEÇÃO DE DADOS (LGPD) E AS COOPERATIVAS: IMPRESSÕES INICIAIS

José RAPHAEL BATISTA FreiRE LEILA ANDRESSA DISSENHA

FORNASIER, Mateus de Oliveira; KNEBEL, Norberto Milton Paiva. 0 titular de dados como sujeito de direito no capitalismo de vigilância e mercantilização dos dados na Lei Geral de Proteção de Dados. Revista Direito e Práxis, [S.l.], v. 12, n. 2, p. 1002-1033, jun. 2021. ISSN 2179-8966. Disponível em: https://www.e-

publicacoes.uerj.br/index.php/revistaceaju/article/view/46944/33907. Acesso em: 20 nov. 2021.

FRANKE, Walmor. Direito das sociedades cooperativas: direito cooperativo. São Paulo: Saraiva. 1973.

FREIRE, José Raphael Batista. A transparência do programa de proteção de dados pessoais nas cooperativas agroindustriais do Estado do Paraná sob as perspectivas jurídica e institucional. Dissertação (Mestrado em Gestão de Cooperativas). Pontifícia Universidade Católica do Paraná. Curitiba, 2021.

GARCIA, Lara Rocha; PINTO, Felipe Chiarello de Souza. Inovação e sua Principal Barreira Jurídica. Revista Eletrônica do Curso de Direito da UFSM, Santa Maria, RS, v. 15, n. 2, e41419, maio/ago. 2020. ISSN 1981-3694. DOI: http://dx.doi.org/10.5902/1981369441419. Disponível em: https://periodicos.ufsm.br/revistadireito/article/view/41419. Acesso em: 20 Nov. 2021.

GARRAT, Roy. Rochdale Equitable Pioneers Society. In: DULFER, Eberhard (ed.). International Handbook of Cooperative Organizations. Germany: Vandenhoeck \& Ruprecht in Göttingen. 1994.

GIDE, Charles. El cooperativismo. Buenos Aires: INTERCOOP- 48. 1974

MASSENO, Manuel David. Como a União Europeia procura proteger os cidadãos-consumidores em tempos de Big Data. Revista Eletrônica do Curso de Direito da UFSM, Santa Maria, RS, v. 14, n. 3, e41708, set./dez. 2019. ISSN 1981-3694. DOI: http://dx.doi.org/10.5902/1981369441708. Disponível em: https://periodicos.ufsm.br/revistadireito/article/view/41708. Acesso em: 20 nov. 2021.

MENDES, Laura Schertel; DONEDA, Danilo. Reflexões iniciais sobre a nova lei geral de proteção de dados. Revista de Direito do Consumidor, vol. 120, p. 469-483, nov./dez. 2018.

NÚMEROS do cooperativismo. Sistema OCB, 2019. Disponível em: https://www.ocb.org.br/numeros. Acesso em: 10 dez. 19.

LIMA, Caio César Carvalho. Objeto, aplicação material e aplicação territorial. In: BLUM, Renato Opice; MALDONADO, Viviane Nóbrega (coord.). Comentários ao GDPR: Regulamento Geral de Proteção de Dados da União Europeia. São Paulo: Thomson Reuters. Brasil, 2018.

LIMA, Caio César Carvalho. In: BLUM, Renato Opice; MALDONADO, Viviane Nóbrega (coord.). Lei Geral de Proteção de Dados comentada. São Paulo: Thomson Reuters. Brasil, 2019.

PARODO, Francesco. La protezione dei dati personali nell'integrazione europea. 2021. Tesi di Dottorato. Dottorato di Ricerca in Scienze giuridiche. Università degli Sudi di Cagliari. Cagliari, 2021. Disponível em: http://hdl.handle.net/11584/313092. Acesso em: 19 nov. 2021. 
ISSN 1981-3694

(DOI): $10.5902 / 1981369441636$

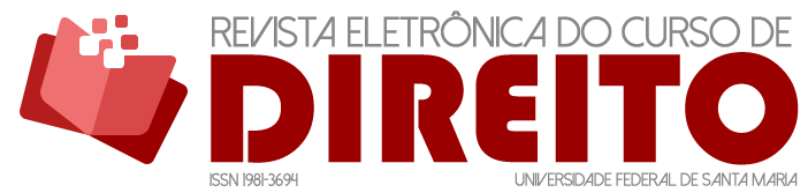

LEI GERAL DE PROTEÇÃO DE DADOS (LGPD) E AS COOPERATIVAS: IMPRESSÕES INICIAIS

José RAPHAEL BATISTA Freire LEILA ANDRESSA DISSENHA

PINHEIRO, Marcos Antonio Henrique. Cooperativas de crédito: história da evolução normativa no Brasil. 6. ed. Brasília: Banco Central do Brasil. 2008. Disponível em:

https://www.bcb.gov.br/content/publicacoes/Documents/outras_pub_alfa/livro_cooperativas credito.pdf. Acesso em: $11 \mathrm{dez} .2019$.

PIURCOSKY, F. et al. A lei geral de proteção de dados pessoais em empresas brasileiras: uma análise de múltiplos casos. SUMA DE NEGOCIOS, 10(23), p. 89-99, julio/diciembre, 2019. ISSN 2215-910X. Doi: http://dx.doi.org/10.14349/sumneg/2019.V10.N23.A2.

RAMOS do cooperativismo. Sistema OCB. Disponível em: https://somoscooperativismo.coop.br/publicacao/57/ramos-do-cooperativismo. Acesso em: 11 de dezembro de 2019.

RAMOS, E. M. B. et al. Questões éticas e perspectiva jurídica da proteção de dados. Cadernos Ibero-Americanos de Direito Sanitário, [S. l.], v. 10, n. 3, p. 172-190, 2021. DOI:

https://doi.org/10.17566/ciads.v10i3.796. Disponível em:

https://www.cadernos.prodisa.fiocruz.br/index.php/cadernos/article/view/796. Acesso em: 20 nov. 2021.

RAMOS, Lara Castro Padilha; GOMES, Ana Virgínia Moreira. Lei geral de dados pessoais e seus reflexos nas ralações de trabalho. Scientia luris, Londrina, v. 23, n. 2, p. 127-146, jul. 2019. DOI: $10.5433 / 2178-8189.2019 v 23 n 2 p 127$. ISSN: 2178-8189.

Regulamento 2016/679 do Parlamento Europeu e do Conselho, de 27 de abril de 2016. Disponível em: https://eur-lex.europa.eu/legal-content/PT/TXT/HTML/?uri=CELEX:32016R0679\&from=EN. Acesso em: 27 mai. 2019.

SANTOS, Fabíola Meira de Almeida; TALIBA, Rita. Lei geral de proteção de dados no brasil e os possíveis impactos. Revista dos Tribunais, vol. 998, p. 225-239, dez., 2018.

SISTEMA OCB. Somos Coop, 2019. Página Inicial. Disponível em: https://www.somos.coop.br/. Acesso em: 21 mai. 2019.

STOEVER, Carlos. Empresa é condenada por divulgar exame toxicológico de funcionário.

Consultor Trabalhista. Disponível em: https://consultortrabalhista.com/noticias/empresa-econdenada-por-divulgar-exame-toxicologico-de-funcionario/. Acesso em: 07 de abril de 2019.

SZINVELSKI, Mártin Marks, ARCENO, Taynara Silva e FRANCISCO, Lucas Baratieri. Perspectivas jurídicas da relação entre big data e proteção de dados. Perspectivas em Ciência da Informação [online], v. 24, n. 04, pp. 132-144, 2019. Disponível em:

https://doi.org/10.1590/1981-5344/4188. Epub 10 Fev 2020. ISSN 1981-5344. Acesso em: 19 nov. 2021.

VOSS, W. Gregory. European union data privacy law reform: General data protection regulation, privacy shield, and the right to delisting. The Business Lawyer, v. 72, n. 1, p. 221-234, 2016. Disponível em: https://hal.archives-ouvertes.fr/hal-02553947/file/TBL\%2072-1_10Voss.pdf.

Recebido em: 14.04.2019 / Aprovado em: 07.10.2021 / Publicado em: 30.11.2021 
ISSN 1981-3694

(DOI): $10.5902 / 1981369441636$

LEI GERAL DE PROTEÇÃO DE DADOS (LGPD) E AS COOPERATIVAS: IMPRESSÕES INICIAIS

\section{COMO FAZER REFERÊNCIA AO ARTIGO (ABNT):}

DISSENHA, Leila Andressa; FREIRE, José Raphael Batista. Lei Geral de Proteção de Dados (LGPD) e as cooperativas: impressões iniciais. Revista Eletrônica do Curso de Direito da UFSM, Santa Maria, RS, v. 16, n. 1, e41663, jan/abr. 2021. ISSN 1981-3694. DOI: http://dx.doi.org/10.5902/1981369441663. Disponível em: https://periodicos.ufsm.br/revistadireito/article/view/41663. Acesso em: dia mês. ano.

Direitos autorais 2021 Revista Eletrônica do Curso de Direito da UFSM

Editores responsáveis: Rafael Santos de Oliveira e Angela Araujo da Silveira Espindola

\section{(c) $(1) \odot$

Esta obra está licenciada com uma Licença Creative Commons Atribuição-NãoComercial-SemDerivações 4.0 Internacional.

\section{SOBRE OS AUTORES}

\section{JOSÉ RAPHAEL BATISTA FREIRE}

Mestre em Gestão de Cooperativas pela Pontifícia Universidade Católica do Paraná (PUCPR). Professor de Graduação e Pósgraduação no curso de Direito da Pontifícia Universidade Católica (PUCPR) - Campus Toledo. Coordenador do Programa de Pós-Graduação em Direito do Agronegócio da Pontifícia Universidade Católica do Paraná (PUCPR) - campus Toledo. Advogado, com ênfase em direito negocial, atuando nas áreas do agronegócio, imobiliário e digital.

\section{LEILA ANDRESSA DISSENHA}

Doutora e Mestra em Direito pela Pontifícia Universidade Católica do Paraná (PUCPR); Especialista em Direito do Trabalho pela PUCPR; Professora TITULAR da PUCPR; Professora de Bases Legais do Cooperativismo do Programa da Pós Graduação em Gestão de Cooperativas da PUCPR (PPGCOOP); Professora de Direito Cooperativo dos cursos in company do ISAE/FGV e do Programa de Compliance do Cooperativismo Paranaense da PUCPR; Professora do Curso de Especialização em Direito do Trabalho e Direito Processual do Trabalho da PUCPR; Professora do Curso de Especialização em Cooperativismo Aplicado da PUCPR. 